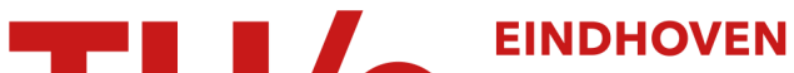 \\ UNIVERSITY OF \\ TECHNOLOGY
}

\section{Production control in a consumer electronics factory}

Citation for published version (APA):

Wijngaard, J. (1987). Production control in a consumer electronics factory. Engineering Costs and Production Economics, 12(1-4), 165-173.

Document status and date:

Published: 01/01/1987

\section{Document Version:}

Publisher's PDF, also known as Version of Record (includes final page, issue and volume numbers)

\section{Please check the document version of this publication:}

- A submitted manuscript is the version of the article upon submission and before peer-review. There can be important differences between the submitted version and the official published version of record. People interested in the research are advised to contact the author for the final version of the publication, or visit the $\mathrm{DOI}$ to the publisher's website.

- The final author version and the galley proof are versions of the publication after peer review.

- The final published version features the final layout of the paper including the volume, issue and page numbers.

Link to publication

\section{General rights}

Copyright and moral rights for the publications made accessible in the public portal are retained by the authors and/or other copyright owners and it is a condition of accessing publications that users recognise and abide by the legal requirements associated with these rights.

- Users may download and print one copy of any publication from the public portal for the purpose of private study or research.

- You may not further distribute the material or use it for any profit-making activity or commercial gain

- You may freely distribute the URL identifying the publication in the public portal.

If the publication is distributed under the terms of Article $25 f a$ of the Dutch Copyright Act, indicated by the "Taverne" license above, please follow below link for the End User Agreement:

www.tue.nl/taverne

Take down policy

If you believe that this document breaches copyright please contact us at:

openaccess@tue.nl

providing details and we will investigate your claim. 


\title{
PRODUCTION CONTROL IN A CONSUMER ELECTRONICS FACTORY*
}

\author{
J. Wijngaard \\ Eindhoven University of Technology, 5600 MB, Eindhoven (The Netherlands)
}

\begin{abstract}
This paper deals with production control in a consumer electronics factory. A short description of the situation and of the actual way of control (Material Requirements Planning) is given. Most attention is paid to modularity. The concept of marketing modularity is introduced
\end{abstract}

to be able to analyze in the advantages of product modularity increasing external flexibility by generating component stocks.

\section{INTRODUCTION}

This paper is concerned with production control in a consumer electronics factory. The factory is part of a multi-national company and takes care of part of the production and distribution network of the company. This has a strong impact on some of the characteristics of the production system. We will give attention to this where necessary.

In the production control concept presently used there are three Production Units, with controlled stocks in between. The three PU's are Automatic Insertion, Manual Insertion and Encasing (see Fig. 1).

In Automatic Insertion, some of the electronic components are inserted mechanically on printed circuit panels ( $\mathrm{pcp}$ ). Components which cannot be inserted mechanically are inserted manually in Manual Insertion. In Encasing, the final assembly takes place.
Stocks are possible between the three Production Units and in front of the first Production Unit. There is only one customer: the Concern Planning Department. The Concern Planning Department allocates the demand to the various plants and determines which demand will be met by which plant. All final products go to the central warehouse before they are distributed to their final destination. This distribution is also part of the task of the Concern Planning Department.

There are about 60 final product types, all with a rather short life cycle ( \pm 2 years) and about 2000 types of components. The product structure is partly modular (see section 4.1 ). The procurement leadtimes vary from 0 to 4 months (see Fig. 2).

The production leadtime is at the moment about 10 days. The added value is $35 \%$. About 170 people are directly employed in production.

*Presented at the Fourth International Working Seminar on Production Economics, Igls, Austria, Feb. 17-21, 1986. 


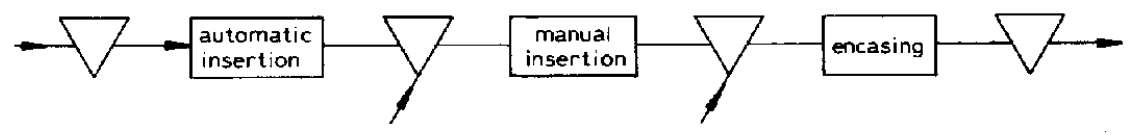

Fig. 1. The goodsflow in the production system.

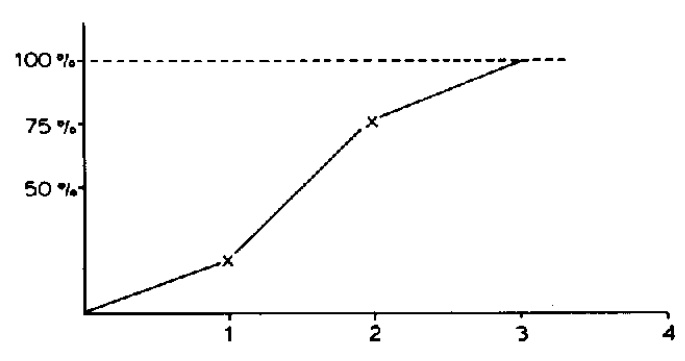

Fig. 2. Cumulative distribution of component leadtimes.

\section{EXISTING PRODUCTION CONTROL SYSTEM}

Two years ago an MRP-system was implemented (MRP: Material Requirements Planning). Since then, the production leadtime has decreased from 25 days to 10 days, the delivery performance has increased, the component stocks have decreased and the utilization rates of manpower capacity and machine capacity have increased.

However, there is still pressure to become more flexible. This causes difficulties because of the long procurement leadtimes: six people are already involved in expediting procurement orders. There is some commonality of components, but this cannot be used effectively because the Master Production Schedule (MPS) is stated in final products. In the next subsection the existing MPS and MRP procedures will be described in more detail.

\subsection{Actual MPS and MRP}

The MPS has a horizon of one year and is at the final product level. For the first 5-9 weeks the resolution level of the MPS is one day (i.e. time buckets of one day). These first 5-9 weeks are the asasembly-plan for the Encasing Department. For the remainder of the horizon the MPS has a resolution level of one week. The MPS over the first 9-13 weeks is frozen at week level, beyond that term a high mix flexibility is required. Every four weeks the MPS is updated. Each week an MRP run is executed. Deviations from the MPS are added to or subtracted from the new first week MPS numbers.

In the MRP run the bill of material (BOM) of the sixty final products is used to determine the component requirement. The production leadtimes used are: 3 days for automatic insertion, 4 days for manual insertion and 3 days for encasing. A safety leadtime of 5 days is added at the component level.

Each week planned orders are calculated from the MRP-run for the three departments. Shop orders are released daily and include checks on material availability.

\subsection{Comment}

The MPS is only checked for encasing capacity and not for other capacities or components. This stems from the time when encasing was the most inflexible part of production. Components are ordered and capacities adjusted (if necessary), based on the results of the MRP-run.There are no material availability simulation possibilities at MPS-level.

Beyond the fixed fence of 9-13 weeks a high mix flexibility is required. Since many components have a leadtime longer than 9 weeks or even 13 weeks this causes difficulties. These difficulties are resolved partially by expediting procurement orders. Six people are continuously involved in this activity. There is some pressure to make the fixed fence even shorter because the stocks in the distribution part of the goodsflow have to be decreased in the future. The factory does not now work for a 
given market segment. Demand is distributed among factories by the Concern Planning Department. Final products are delivered by the factories to the central warehouse. The stocks in the central warehouse and the distribution of final products are controlled by the Concern Planning Department. Such an organization implies that there is a lot of slack and flexibility in the distribution part of the goodsflow; requirements are generally not very firm; bargaining is possible.

This will change in the future when a fixed market segment will be assigned to this factory. Then the factory will be much "closer" to the real customer and factory flexibility will become more important. The question is how to realize this flexibility as efficiently as possible. The following possibilities can be distinguished:

(1) reduce procurement leadtimes

(2) reduce production leadtime

(3) create coordinated slack at component level (safety stocks, overplanning)

The first possibility is the most important one. Reduction of procurement leadtimes helps most in increasing the flexibility. It is assumed that this is given attention anyways. Here the other two possibilities will be considered.

In the actual way of control, the three production stages (automatic insertion, manual insertion and encasing) are modelled in the MRP-system as three separate stages. That implies that for each stage one needs to release a shop order again. That slackens unnecessarily the speed of the production process. This is discussed in the next section. It will be argued that it is possible to treat all production stages together as one MRP-stretch.

Component availability is the most inflexible part of the manufacturing process. It is possible to generate slack by safety stocks or overplanning at component level. But the slack in the availability of the different components should be coordinated to make it effective. In section 4 the coordinated creation of slack is related to product structure and marketing structure.

\section{INTERNAL FLEXIBILITY}

To show that it is possible to include all production stages into one release stretch it is necessary first to analyse the (internal) flexibility of the manufacturing process. This is done in subsections $3.1,3.2$ and 3.3. In subsection 3.4 we state that one release stretch is sufficient.

\subsection{Automatic insertion}

Part of the components are inserted mechanically. There are two types of machines: machines for horizontal insertion and machines for vertical insertion. There are 4 machines for each type of insertion. The products require both horizontal insertion of some components and vertical insertion of other components. Within horizontal insertion, viz. vertical insertion, the machines are substitutable. Components are fed to a machine from containers attached to it. A change-over from one panel to another takes only 2 minutes as long as the right feeders are attached. Replacing feeders takes 10 minutes. Personnel in this department work in three shifts ( 5 on each shift). The machine utilization rate is $85 \%$. Machine disturbances of up to 1 hour occur with an average downtime of $5 \%$.

\subsection{Manual insertion}

The main activity in this department is the manual insertion of components which cannot be inserted mechanically, testing of panels and repair of panels (if possible). Insertion and testing is organized in product groups: a certain set of panels is assigned to each group. $50 \%$ of the personnel is part-time. This generates an irregular availability pattern during the week. However, there is a high mobility of personnel. If necessary, people can switch from one group to another. Repair work is done by a separate group of personnel. But there are also people ( so called "butterflies") who can be deployed as well in repair work as in insertion and testing. Equipment is rather inexpensive and is 
overcapacitated. The number of butterflies and the mobility is kept so high that it is sufficient to check the workload for this department only on one dimension.

Personnel in this department (about 100 people) work on one shift. Overtime is possible and can be arranged within one day. About $10 \%$ of the time is spent on training and job consultation. These activities, however, can be postponed in case of a high requirement for production orders. There is some mobility between manual insertion and encasing.

\subsection{Encasing}

There are 6 encasing groups. Each type of final product is assigned to one group, but in case of an unbalanced work-mix it is possible to use alternative groups.

Personnel in this department (about 50 people) work on one shift. Usage of overtime is possible and can be arranged in one day. There is some mobility between encasing and manual insertion.

\subsection{One release stretch}

In the actual way of control, three phases of production are considered, with controlled stock points in between. For each phase one has to release orders. This includes checking the material availability, picking the components and reporting the finishing of the order. Considering the internal flexibility of the factory, it does not seem to be necessary to distinguish three phases of production. There are no severe changes in the demand or production uncertainty (see ref. [1]). The changes in demand uncertainty get even smaller if the production leadtime can be reduced. Because of changeover times for automatic insertion there is some lot-sizing there, but the manpower is so flexible that manual insertion and encasing can follow these lot-sizes. There will be some inventory between automatic insertion and manual insertion because in automatic inser- tion people work on three shifts and in manual insertion and encasing on one shift. But this does not make it necessary to distinguish separate production phases. We propose to let the whole production be included in one production phase and to use some JIT-type system for the internal control of that phase. See refs. [2] and [3] for details concerning this internal control and the operational characteristics of the production phase.

\section{PRODUCT STRUCTURE, MARKETING STRUCTURE AND COORDINATED SLACK}

Component availability is the main determinant of the short term flexibility of production. The component availability determines what products can be assembled at short term. However, there are about 2000 component types and that makes the insight in the production possibilities not very operational. This can be improved in case of a modular or partly modular product structure. In that case it is only necessary to consider the availability of relatively few sets of components. Modularity of product structures is considered in subsection 4.1 .

A modular product structure makes it possible to express the short term production flexibility in few dimensions, namely the availability of the component sets. This suggest to formulate the MPS also at component level: it is an easy way to make the MPS realistic. Coordinated slack can be realized then by overplanning the MPS. The need for flexibility follows from the demand and marketing structure. This is discussed in subsection 4.2. See ref. [4], chapter 8 , for an introduction into modularity and Master Production Scheduling.

\subsection{Product structure}

Each type of final product is completely determined by five basic function dimensions 
( $A, B, C, D, E$ ), four options (I, II, III, IV) and one destination dimension $(G)$.

The number of possibilities on each of the basic function dimensions is two: $(A(1), A(2)$, $B(1), B(2), \ldots)$. The options can be added or not. The number of possibilities on the destination dimension is four $(G(a), G(b), G(c)$, $G(d))$. A specific type of final product $F_{p}$ is, for instance,

$(A(1), B(2), C(2), D(1), E(2), \mathrm{I}(-)$, $\mathrm{II}(-), \operatorname{III}(+), \operatorname{IV}(+), G(b))$.

Not all combinations are possible of course, otherwise there would be $2^{5} \cdot 2^{4} \cdot 4=2000$ types of final product instead of 60 .

The product structure is partly modular. If the product structure were completely modular it would be possible to define parts sets,

$C$ (Commons)

$A(1), A(2), B(1), B(2), C(1), C(2), D(1)$, $D(2), E(1), E(2)$

I, II, III, IV

$G(a), G(b), G(c), G(d)$

such that the material requirement of each of the final products were the sum of the material requirements from each of the actual alternatives and options. The material requirement for a final product of the just mentioned type $F_{p}$ would be

$C, A(1), B(2), C(2), D(1), E(2)$, III, IV, $G(b)$

The product structure of this final product $F_{p}$ could be depicted as in Fig. 3.

Unfortunately the product structure is not completely modular. Occurrence of certain components depends on combinations of dimensions. For final product $F_{p}$, for instance, some components are needed which are specific for the combination $A(1) \times B(2)$. Similarly there are components which depend on combinations of basic function and option, on combinations of basic function and destination, on combinations of option and option, or on combinations of option and destination (see Fig. 4).

The number of parts sets necessary to describe the component requirement of all types of final product is about 50 . In case of a completely modular structure this would have been 19 .

In the design of new generations of final products one tries to make the component requirement more and more modular.

The time-phased availability of the component sets determines the short term flexibility of manufacturing. The exact time-phased availability of a certain component set is the minimum of the time-phased availabilities of the components in that set. This means that to check the time-phased availability of a component set one has to use information about inventories and scheduled receipts of all components involved. This complicates the flexibility check. A compromise of exactness and complexity is to consider not all components, but only the most critical ones (long leadtime, expensive) (see ref. [5]).

\subsection{Marketing structure}

By overplanning at component set level it is possible to generate coordinated slack which is short term (mix) flexibility. The amount of slack necessary depends on the marketing structure. It is necessary to express marketing and sales possibilities and restrictions in the same dimensions, as manufacturing possibilities, so in component sets. This is considered in this subsection.

A customer order can be characterized by the dimensions determining the final product (see subsection 4.1) and dimensions characterizing the customer. For the sake of convenience we assume that a customer is characterized by only one dimension, $M$, with $n$ possibilities on this dimension $(M(1), M(2), \ldots, M(n)$ ) (think of market segments). An order from a customer of type $m$ for a product of type $F_{p}$ is characterized by:

$(A(1), B(2), C(2), D(1), E(2), \mathrm{I}(-), \mathrm{II}(-)$, $\mathrm{III}(+), \mathrm{IV}(+), G(b), M(m))$.

Let $p(A(1), B(2), C(2), \ldots, G(b), M(m))$ be the fraction of orders of this type. The require- 


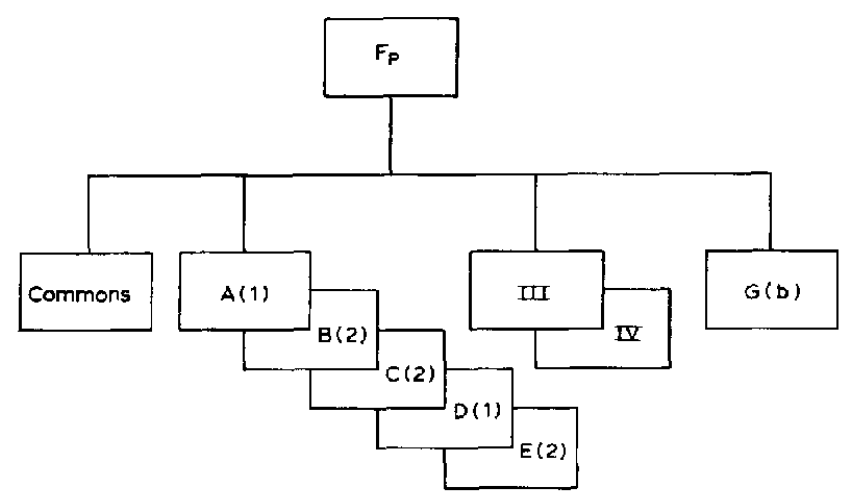

Fig. 3. Modular product structure.

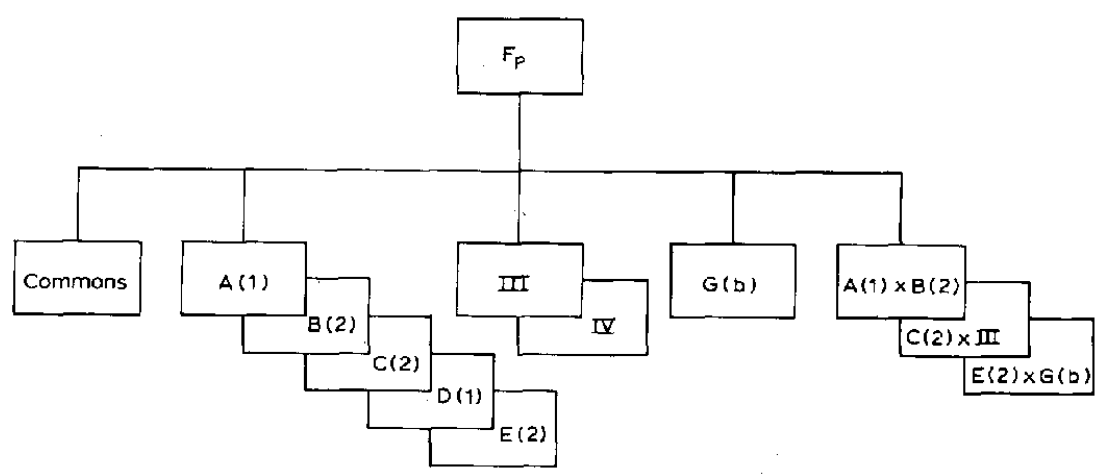

Fig. 4. Partly modular product structure.

ment of parts set $A(1)$ is determined by

$p(A(1)):=\sum_{x=A(1)} p(x, \ldots)$

The requirement of parts set $A(1) \times B(2)$ is determined by

$p(A(1) \times B(2)):=\sum_{\substack{x=A(1) \\ y=B(2)}} p(x, y, \ldots)$

Similarly for the other parts sets.

The required component flexibility depends on the uncertainty with respect to these fractions.

As one can speak of a modular product structure, one can speak of a modular marketing structure: the marketing structure is called modular if the fraction of a certain type of customer orders may be estimated as the product of the estimates of the fractions of the actual options and alternatives. For instance

$$
\begin{aligned}
& \hat{p}(A(1), B(2), C(2), \ldots, M(m)) \\
& \quad=\hat{p}(A(1)) \cdot \hat{p}(B(2)) \\
& \quad \cdot \hat{p}(C(2)) \cdot \ldots \hat{p}(G(b)) \cdot \hat{p}(M(m))
\end{aligned}
$$

This implies that

$\hat{p}(A(1) \times B(2))=\hat{p}(A(1)) \cdot \hat{p}(B(2))$

The most straightforward form of modularity is when the demand may be represented by a multi-nomial model: the demand is generated by a set of independent lotteries, one for each of the basic dimensions. It is only necessary then to estimate the distributions on the basic dimensions $(\hat{p}(A(i)), \hat{p}(B(i)), \ldots)$. These distributions may be more stable than the combined distribution and there may be more 
empirical material available to estimate these distributions than to estimate the combined distribution. See appendix for details. It may also be so that the demand is not purely stochastic, but that there is some short term control on certain dimensions (directed campaigns) or foreknowledge with respect to the distribution over certain dimensions (contracts).

A modular marketing structure and a modular product structure make it easy to relate marketing intelligence to production intelligence. See ref. [6] for the information system consequences. It is clear, however, that in this case there is no complete marketing modularity. For marketing modularity would imply the existence of all combinations, so the existence of (about) 2000 final products instead of 60 . There are numerous absolute dependencies between dimensions. There may also be some less absolute dependencies. That makes it difficult to formulate marketing and sales intelligence in basic dimensions rather than in final products. This complicates the MPS-process: marketing intelligence and production intelligence do not fit. It leads to a situation where the MPS is easily interpreted as demand instead of the result of coordination of production on one hand and marketing and sales on the other hand. See ref. [7] for methods to determine the appropriate amount of slack in case of such a demand interpretation. See also ref. [8].

But also in this case of very incomplete marketing modularity it is useful to aim at product modularity. Because that makes it easier (coordination via component sets) and cheaper (higher commonality) to generate flexibility at component level. In the long run, it may also lead to a higher marketing modularity.

\section{REFERENCES}

1 Bertrand, J.W.M., and Wijngaard, J. (1984). The structuring of production control systems. Report ARW 03 THE BDK/ORS/84/10, Eindhoven University of Technology.
2 De Koster, M.B.M. (1986). Capacity analysis of two-stage production lines with many products. Paper presented at the Fourth International Working Seminar on Production Economics, Igls/Innsbrück, February 1986. Eng. Costs and Production Economics, 12(1-4): 175-186.

3 Wijngaard, J. (1985). Production control in a consumer electronics factory. Report BDK/ORS/85/14, Eindhoven University of Technology.

4 Vollmann, T.E., Berry, W.L. and Whybark, D.C. (1984). Manufacturing Planning and Control Systems. Dow-Jones/Irwin.

5 Sødahl, L.O. (1981). How do you Master Schedule half a million Product Variants? APICS Conference Proceedings.

6 Wortmann, J.C. (1986). Information systems for assemble to order production. Paper presented at the Fourth International Working Seminar on Production Economics, Igls/Inssbrüick, February 1986. Eng. Costs and Production Economics, 12(1-4): 187-194.

7 Van Donselaar, K. and Wijngaard, J. (1986). Commonality and safety stocks. Paper presented at the Fourth International Working Seminar on Production Economics, Igls/Inssbrück, February 1986. Eng. Costs and Production Economics, 12(1-4): 197-204.

8 Wijngaard, J. and Wortmann, J.C. (1985). MRP and inventories. Eur. J. Oper. Res., 20: 281-293.

\section{APPENDIX}

\section{Modularity}

In section 4 it has been argued that product structure modularity and marketing structure modularity simplify the formulation of a realistic Master Production Schedule and make the generation of coordinated slack at component level cheaper. Marketing structure modularity has been formulated there as the property that the fraction of customer orders of a certain type may be estimated as the product of the estimates of the fractions of the actual options and alternatives

$$
\begin{aligned}
& \hat{p}(A(1), B(2), C(2), \ldots, G(b), M(m)) \\
& =\hat{p}(A(1)) \cdot \hat{p}(B(2)) \cdot \hat{p}(C(2)) \cdot \ldots \cdot \hat{p}(G(b)) \\
& \cdot \hat{p}(M(m))
\end{aligned}
$$

To make this more precise we have to introduce a formal demand model.

The most straightforward model is a multinomial model for the demand per type of customer order. This model is based on the assumption that all order sizes are one and that 
the generation of customer orders is the result of a lottery in which a fixed number of customer orders are drawn with each type of customer order having a fixed probability to be drawn. In case of order size equal to one the assumption that a given number of customers is drawn is equivalent to the assumption of given total demand. This is not too unrealistic because the fluctuations in total demand are much smoother than the fluctuations in the demand per product.

Main determinant for the slack required at parts-set level is the uncertainty of the partsset demand and the unreliability of the partsset demand forecasts. Consider a certain partsset $S$. Let $p$ be the probability that a customer orders a final product which uses this parts-set. Let $N$ be the demand per period, then the demand for this parts-set in the periods $t, t+1, \ldots, t+T-1$, denoted by $d^{T}(t)$, follows a distribution with mean $T N p$ and variance $T N p(1-p)$. This demand has to be forecasted as $T N \hat{p}$ with $\hat{p}$ the most actual estimate of $p$. That implies that the forecast error consists of two parts:

$d^{T}(t)-T N p$ and $T N(p-\hat{p})$

The variance of the first part is $T N p(1-p)$. The variance of the second part depends on the length of the history which may be used to estimate $p$. Suppose that $H$ periods may be used to estimate $p$ ( $p$ may be assumed to be constant during the last $H$ periods), then $p$ should be estimated as follows

$\hat{p}=\frac{d^{H}(t-H)}{H N}$

assuming that the total demand has been equal to $N$ during the last $H$ periods. In this expression $d^{H}(t-H)$ stands for the demand in the periods $t-H, \ldots, t-1$. the mean of $\hat{p}$ is equal to $p$ indeed, its variance is equal to

$$
\frac{H N p(1-p)}{(H N)^{2}}=\frac{p(1-p)}{H N}
$$

That implies that the variance of $T N(p-\hat{p})$ is equal to

$\frac{(T N)^{2}}{H N} p(1-p)$

The total variance of the forecast error of $d^{T}(t)$ is

$T N p(1-p)\left(1+\frac{T}{H}\right)$

In case of $p$ small this is about equal to

$T N p\left(1+\frac{T}{H}\right)$

The slack in each of the parts-sets has to cover the uncertainty in the demand over the procurement leadtime. The required slack is proportional to $\sqrt{N p}$. In case the parts-set is split up in two different types of parts-set (so, less commonality), with about equal average demand $\left(\frac{1}{2} N p\right)$, the required slack is proportional to $2 \sqrt{\frac{1}{2} N p}=\sqrt{2 N p}$. This shows how improved product structure modularity decreases the required slack at parts-set level.

The effect of marketing structure modularity is more difficult. Marketing structure modularity in this multi-nomial case means that the distributions on the various dimensions are independent: the generation of customer orders is the result of independent lotteries on all dimensions. So, for instance,

$$
\begin{aligned}
& p(A(1), B(2), C(2), \ldots, G(b), M(m)) \\
& =p(A(1)) \cdot p(B(2)) \cdot p(C(2)) \cdot \ldots \\
& \quad \cdot p(G(b)) \quad \cdot p(M(m))
\end{aligned}
$$

In case of incomplete product structure modularity there exist parts sets of the following type: $A(1) \times B(2)$. Marketing modularity makes it possible now to estimate $p(A(1) \times B(2))$ by

$\hat{p}(A(1) \times B(2)):=\hat{p}(A(1)) \cdot p(B(2))$

The variance of this estimate of $p$ can be calculated using the variances of $\hat{p}(A(1))$ and $\hat{p}(B(2))$ and turns out to be equal to 


$$
\begin{aligned}
p \frac{(A(1)) \cdot p(B(2))}{N}\{ & p(A(1))+p(B(2)) \\
& -2 p(A(1)) \cdot p(B(2))\}
\end{aligned}
$$

while the variance of a direct estimate of $p(A(1) \times B(2))$ would have been equal to

$p \frac{(A(1)) \cdot p(B(2))}{N}\{1-p(A(1) p(B(2))\}$

The second variance is larger, the difference is

$$
\begin{aligned}
& p \frac{(A(1)) p(B(2))}{N}\{1-p(A(1))-p(B(2)) \\
& +p(A(1)) p(B(2))\} \\
& =p \frac{(A(1)) p(B(2))}{N}\{1-p(B(2))\}\{1 \\
& -p(A(1))\}
\end{aligned}
$$

This shows that the difference gets larger if there are more possibilities on each dimension (smaller $p(A(1))$ and $p(B(2))$. In case of a parts-set defined by three dimensions, for instance $A(1) \times B(2) \times C(2)$, the difference between the variance of the direct estimate and the variance of the indirect estimate also gets larger.

This shows that marketing structure modularity is useful in reducing the forecast error of the demand per parts set. We have split the forecast error in two parts:

$d^{T}(t)-T N p$ and $T N(p-\hat{p})$

It is important to note here that marketing modularity in a multi-nomial model only reduces the variance of the second part of the forecast error $(T N(p-\hat{p}))$. This variance is in case of no marketing structure modularity $T / H$ times the variance of the first part. That means that if the relevant history $H$ is much longer than the interval $T$ over which demand has to be forecasted, then this second variance is much smaller, even in case of no modularity, than the first variance and the influence of modularity on the total variance of the forecast error is relatively small.

This suggests that marketing structure modularity is not very important. However, there are other, less quantifiable effects of marketing structure modularity. Marketing structure modularity means that there are only few relevant dimensions and that special features of each of these dimensions are not disturbed by the distribution on the other dimensions. This generates, for instance, the following possibilities:

-The relevant history to estimate the distribution on one dimension is longer than the relevant history of the other dimensions (for instance, the distribution on the destination dimension).

-The distribution over certain dimensions may be estimated using the demand figures of other types of products with comparable dimensions. For instance, the distribution over the destination dimension may also be based on demand figures of other types of consumer electronic products, not produced in this factory.

-It is possible that there is no uncertainty on certain dimensions, for instance because of contracts formulated in these dimensions.

These type of possibilities are probably a more important contribution of marketing structure modularity than the direct effect of being able to estimate the probability of combinations of dimensions more precise.

We have assumed here (see section 4.2) that there is only one customer dimension. The advantages of modularity, however, are also a reason to split up the one customer dimension $(m)$ in as many as possible independent dimensions. This is the main problem of marketing intelligence. 